DOI: https://doi.org/10.47405/aswj.v7i1.196

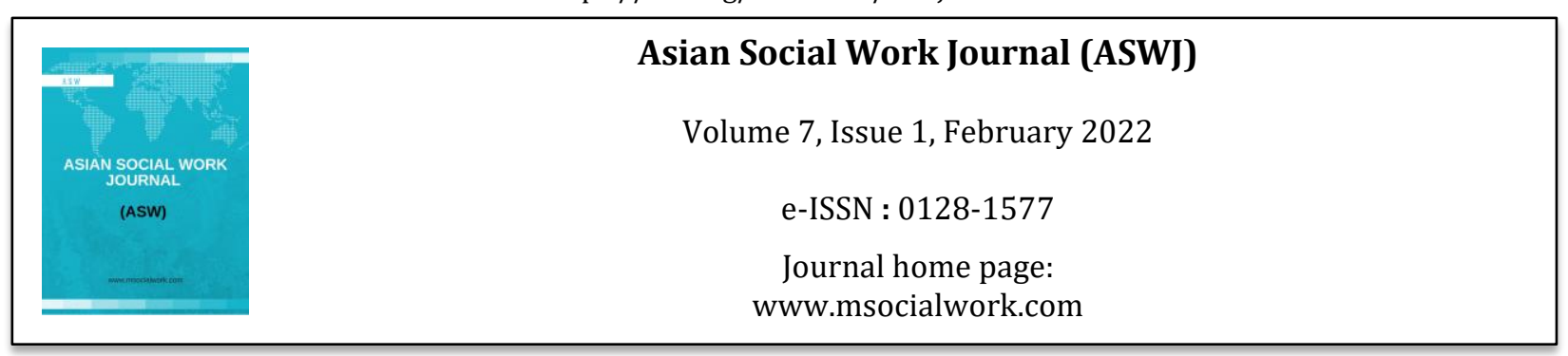

\title{
Caregiver Stress in Dealing with Traumatic Brain Injury Family Members
}

\author{
Paramjit Singh Jamir Singh ${ }^{1}$, Azlinda Azman ${ }^{1}$, Rajwani Md. Zain ${ }^{2}$ \\ ${ }^{1}$ Social Work Programme, School of Social Sciences, Universiti Sains Malaysia, Penang, Malaysia \\ ${ }^{2}$ College of Arts and Sciences, School of Applied Psychology, Social Work and Policy, Universiti Utara Malaysia, Kedah, \\ Malaysia \\ Correspondence: Paramjit Singh Jamir Singh (paramjit@usm.my) and \\ Azlinda Azman (azlindaa@usm.my)
}

\begin{abstract}
Traumatic brain injury (TBI) is sudden damage to the brain caused by a jolt or blow to the head. The common causes of TBI are due to falls, sports injuries, and car or motorcycle crashes. TBI can be classified into several types, ranges from a mild concussion to severe permanent brain damage. Nevertheless, the impacts of TBI are quite devastating not only to the patient but also on the family. It may last for several years, hence the affected patient definitely requires ongoing care which is normally provided by informal caregivers, such as spouses, parents, or other family members. In addition, TBI can cause drastic changes to the life of the family members. The caregiver's stresses including psychological problems, family burdens, changes in behavior and changes in social roles will be discussed critically in this article. Based on the literature, many caregivers lack good coping strategies in dealing with their stress. More well-designed interventions is an absolute necessity among TBI family caregivers to lessen the stress and improve their social wellbeing and functioning.
\end{abstract}

Keywords: Traumatic Brain Injury, Family Caregivers, Stresses, Well-Designed Interventions

\section{Introduction}

Traumatic brain injury (TBI) is a non-hereditary condition where the brain is damaged and possibly affects cognitive, physical, and psychosocial functions with an associated diminished or altered state of consciousness, temporarily or permanently. This type of injury is originated from an external mechanical force (Tabish, Lone, Afzal, \& Salam, 2006). Consequently, TBI influences the roles and responsibilities within the family due to the behavioural changes of TBI family members. The daunting role of taking care TBI family members usually made the caregivers feel that their life is not their own and in the worst case, they are not able to pursue their own interests and social life. Caregivers typically have to assume the main role of the family as the responsibilities bear by their loved one now shifted to them. Now they have to manage the housework, finance, and they have to take care of the TBI family member all simultaneously. Despite increase of workload, there is less support to help caregivers to cope with this dreary situation. Hence, TBI disrupts the family life, since many patients require continuing care (Tennant, Macdermott, \& Neary, 1995) and the responsibility of care is mostly provided by family members and spouses (Knight, Devereux, \& Godfrey, 1998). 
DOI: https://doi.org/10.47405/aswj.v7i1.196

\section{Impact of Traumatic Brain Injury on Caregivers}

\section{Psychological Problems}

According to the literatures, caregivers of TBI family members often suffer psychological problems including depression, anxiety, stress and burden (Sander, High, \& Hannay, 1997; Knight, Devereux, \& Godfrey, 1998; Watanabe, Shiel, Asami, Taki, \& Tabuchi; Rivera, Elliott, Berry, Grant, \& Oswald, 2007).Statistic shown that approximately $48-60 \%$ of caregivers looking after a person with TBI may experience depression (Douglas, \& Spellacy, 2000; Rivera et al, 2007). In addition, Brookes, Gampsie, Symington, Beattie, and McKinlay, (1986) found that caregiver stress level was higher at five years post-injury than one year after the injury. Due to the stress experienced by the caregivers, it affects several aspects of their lives including their ability to carry out household or work responsibilities. As a result, the whole family quality of life deteriorated significantly. Kreutzer, Gervasio, and Camplair, (1994) stated that the characteristic of families of TBI patients are similar to families of psychiatric patients. These families had 'unhealthy' family functioning.

Meanwhile, spouses were more susceptible to these psychological crises as compared to biological parents, considering parents are more inclined to assume the role as carer and provider (Blake, 2013). Regarding on how the gender of caregivers vent out their stress, Kreutzer, Gervasio, and Camplair (1994) asserted that females express psychological depression and anxiety. On the other hand, males exhibit exhaustion and agitation. In addition, spouses were more prone to succumb to depression as compared to the biological parents because of losing their marital partner, acquaintance, and child nurturing partner pertinent to the damaging effects of TBI.

\section{Family Burdens}

McKinlay, Brooks, and Bond (1981) conducted a longitudinal study on investigating primary caregivers of patients with TBI at 3,6 and 12 months post-injury and found out that there was a slight increased burden after 6 and 12 months. In another study by the same authors, it was revealed that caregivers suffered a significantly higher burden at 5 years compared to 1 year post-injury (Brooks et al., 1986). Livingston, Brooks, and Bond (1985) confirmed that there was a high level of burden at all time points, with a slight increase in burden at 6 and 12 months from their investigation on 57 caregivers of patients with severe TBI. Another similar investigation from New Zealand also asserted that $50 \%$ of the caregiver's experienced significant burden at both 6 and 12 months post-injury, nevertheless there was no change in burden over time (Marsh, Kersel, Havill, \& Sleigh, 1998). Johnson (1995) also have proven that there is a higher burden in caregivers of TBI patients compared to caregivers of patients with other acquired brain injuries. However, a finding by Sander, High, and Hannay (1997) refuted these claims, as she discovered decrease in perceived burden during the first year after injury in their investigation of 69 caregivers at 3 different follow-up times within the first year post injury.

\section{Changes in Behaviour}

Previous studies contended that one of the most common and strongest reasons of psychological distress and family functioning are changes in behaviour related to TBI (Weaver, Perloff, \& Waters, 1999). Toseland, Rossiter, and Peak (1990) suggested that the behaviours of TBI patients, especially aggression, had the most severe and inescapable impacts on all aspects of caregiver functioning. Qadeer, Khalid, Amin, Murtaza, Khaliq, and Shoaib (2017) used path analysis on families following severe TBI to examine the effect of neurobehavioral problems on family functioning and psychological distress using the Family Assessment Device Mark (Qadeer, et al, 2017). Chronic stressors for instance, cognitive, physical, behaviour, communication and social problems were identified in this investigation. They recognised that behavioural changes were the strongest predictors of poor family functioning. Prior quantitative research generally stated that challenging behaviours exhibited by TBI patients, notably emotional control changes and aggression are strong predictors of family burden and distress (Qadeer, et al, 2017). Moreover, these behaviours are deemed far more imperative compared to physical or functional changes (Qadeer, et al, 2017). 
DOI: https://doi.org/10.47405/aswj.v7i1.196

\section{Changes in Social Roles}

Changes to social roles, disturbances in their relationship with the TBI members, a decrease in leisure time and a reduced social circle and contact with friends are inevitable effects suffered by the caregivers. Furthermore, Romano (1974) and Lezak (1988) highlighted that majority of the caregivers felt lonely and socially isolated. They also have to take greater domestic workload and possibly greater responsibilities such as looking after children, becoming a breadwinner or managing finances (Kreutzer et al, 1994).

\section{Factors Alleviating Caregiver Stress}

Caregiver's ability in dealing with stress is influenced significantly by the caregiver's characteristics. Previous study conducted on 60 caregivers by Rivera et al (2007) have confirmed that caregivers of persons with TBI who sustained physical health problems and showed ineffective problem-solving are susceptible to depression after completing the Centers for Epidemiologic Studies-Depression scale. Contrarily, the study found out that time spent as caregivers does not play an important role to the problem.

\section{Coping Strategies and Social Support}

TBI coping strategies are extensively recorded in the literature (Frank, Haut, \& Smick, 1990). Even though there is few number of research on caregiver coping strategies, it has become a growing area of study (Minnes, Graffi, Nolte, Carlson, \& Harrick, 2000). Wells, Dywan, and Dumas (2005) asserted that coping strategies are essential since life satisfaction of the caregiver has shown to be positively affected by coping styles. Examples of coping strategies adopted by TBI caregivers such as cognitive restructuring or reframing, main training enjoyable activities and pursuing emotional support through organized family support groups are well-documented in (Wells, et al, 2005).

Another viable form of coping strategies is social support. Social support has been proposed as a mediator of caregiver stress and depression. Frank et al (1990) discovered that caregiver depression was predicted by the number of adverse effects on family members in a study conducted on 58 caregivers. The impact of negative family effects on caregiver depression was alleviated the effectiveness of social support.

Furthermore, some studies related to social support suggested that caregivers with stronger social support ties are less likely to experience depression (Douglas \& Spellacy, 2000). Knight et al. (1998) validated that social support is not associated with caregiver burden. Recent study using the Caregiver Appraisal Scale and the Social Provision Scale also demonstrated that perceived social support alone was the biggest factor in perception of caregiving 'mastery' and satisfaction with the caregiving relationship (Rivera et al, 2007). Hence, this implies that development of interventions in strengthening social support networks is essential.

\section{Conclusion}

It is unquestionable fact that caregiving for persons with TBI can be a stressful role. A long-term care for TBI patients definitely requires supporting caregivers. Studies have identified various factors related to caregiver distress and differences between predictors of stress for particular caregiving groups, such as spouses or parents. Interventions such as provision of information, support groups and self-help resources, family support and counselling, caregiver training and respite care may help to reduce stress. Nonetheless, due to difference in in design and methodology recorded in literature, it is quite challenging to compare and generalize the findings. The literature lacks in large-scale controlled trials to evaluate the outcome of interventions for caregivers of people with TBI. Therefore, more well-designed research is required to evaluate the impact of interventions in reducing stress within caregivers of brain-injured individuals. Findings also prove that many caregivers lack good coping strategies in dealing with their stress. In addition, it is worth mentioning that social support groups 
DOI: https://doi.org/10.47405/aswj.v7i1.196

consist of caregivers who have similar experiences in caring for the TBI family members can assist the affected caregivers. These groups can act as a source of information and provide positive coping strategies for the affected caregivers. Last but not least, more well-designed interventions are an absolute necessity among TBI family caregivers to alleviate the stress and improve their social wellbeing and functioning.

\section{Acknowledgement}

This work was supported by the Trans Disciplinary Research Grant Scheme (TRGS) (203/PSOSIAL/6768001).

\section{References}

Blake, H. (2013). Caregiver stress in traumatic brain injury. Int J Ther Rehabil, 263-271.

Brooks, N., Gampsie, L., Symington, G., Beattie, A., \& McKinlay, W. (1986). The five year outcome of severe blunt head injury: A relative's view. J Neurol Neurosurg Psychiatry, 49, 764-770.

Douglas, J., \& Spellacy, F. (2000). Correlates of depression in adults with severe traumatic brain injury and their carers. Brain, 14 (1), 71-88.

Frank, R., Haut, A., \& Smick, M. (1990). Coping and family functions after closed head injury. Brain Inj, 4, 289-295.

Johnson, B. (1995). One family's experience with head injury: A phenomenological study. Journal of Neuroscience Nursing, 21 (2), 113-18.

Knight, R., Devereux, R., \& Godfrey, H. (1998). Caring for a family member with a traumatic brain injury. Brain Inj, 12, 467-481.

Kreutzer, J. S., Gervasio, A.H., \& Camplair, P.S. (1994). Patient correlates of caregivers' distress and family functioning after traumatic brain injury. Brain Injury, 8, 211-230.

Kreutzer. J., Gervasio, A., \& Camplair, P. (1994). Primary caregivers' psychological status and family functioning after traumatic brain injury. Brain Inj, 8, 197-210.

Lezak, M. (1988). Brain damage is a family affair. J Ciin Exp Neuropsychot, 10, 111-123.

Livingston, M., Brooks, D., \& Bond, M. (1985). Three months after severe head injury: Psychiatric and social impact on relatives. J Neurol Neurosurg Psychiatry, 48, 870-875.

Marsh, N., Kersel, D., Havill, J., \& Sleigh, J. (1998). Caregiver burden at 6 months following severe traumatic brain injury. Brain, 12, 225-238.

McKinlay,W., Brooks, D., \& Bond, M. (1981). The short term outcome of severe blunt head injury as reported by relatives of the injured person. J Neurol Neurosurg Psychiatry, 44, 527-533.

Minnes, P., Graffi, S., Nolte, M., Carlson, P., \& Harrick, L. (2000). Coping and stress in Canadian family caregivers of persons with traumatic brain injury. Brain Inj, 14, 737-748.

Qadeer, A., Khalid, U., Amin, M., Murtaza, S., Khaliq, M.F., \& Shoaib, M. (2017). Caregiver's burden of the patients with traumatic brain injury. Cureus, 9 (8), 1-8.

Rivera, P., Elliott, T.R., Berry, J.W., Grant, J.S., \& Oswald, K. (2007). Predictors of caregiver depression among community-residing families living with traumatic brain injury. NeuroRehabilitation, 22 (1), 3-8.

Romano, M. (1974). Family responses to traumatic head injury. Scand J Rehabil Med, 6, 1-4.

Sander, A., High, W., \& Hannay, H. (1997). Predictors of psychological health in caregivers of patients with closed head injury. Brain, 11, 235-49.

Tabish, A., Lone, N.A., Afzal,W.M., \& Salam, A. (2006). The incidence and severity of injury in children hospitalised for traumatic brain injury in Kashmir. Injury, 37 (5), 410-15.

Tennant, A., Macdermott, N., \& Neary, D. (1995). The long-term outcome of head injury: implications for service planning. Brain Inj, 9 (6), 595-605.

Toseland, R.W., Rossiter, C.M., \& Peak, T. (1990). Comparative effectiveness of individual and group interventions to support family caregivers. Soc Work, 35, 209-217.

Watanabe, Y., Shiel, A., Asami, T., Taki, K., \& Tabuchi, K. (2000). An evaluation of neurobehavioural proljlems as perceived by family members and levels of family stress 1-3 years following traumatic brain injury in Japan. Clin Rehabil, 14, 172-177. 
DOI: https://doi.org/10.47405/aswj.v7i1.196

Weaver, F.M., Perloff, L., \& Waters, T. (1999). Patients' and caregivers' transition from hospital to home: Needs and recommendations. Home Health Care Serv Q, 17, 27-48.

Wells, R., Dywan, J., \& Dumas, J. (2005). Life satisfaction and distress in family caregivers as related to specific behavioural changes after traumatic brain injury. Brain Inj, 19 (13),1105-11I5. 